\section{ELEMENTOS CONSTITUTIVOS DE UM DESASTRE CATASTRÓFICO: OS PROBLEMAS GIENTÍFICOS POR DETRÁs dos CONTEXTOS GRITICOS}

\section{Norma Valencio}

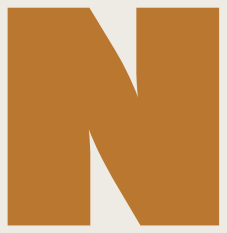

a década de 1990, num debate ainda inconcluso sobre a definição de desastre, a maior autoridade contemporânea no assunto mencionou que os países em desenvolvimento provavelmente elaborariam uma definição radicalmente diferente (1) das prevalentes nos EUA e Europa, que já não eram mais aceitas pacificamente em seu próprio contexto. Os embates se estenderam ao uso do qualificativo "natural" associado a desastre (2), termo adotado até por organismos multilaterais (p. ex., 3). A crítica mais contundente é a de que isso perpetua a confusão entre eventos da natureza - como inundaçôes, terremotos, erupções vulcânicas, tempestades, tsunamis, secas e afins - e os desastres propriamente ditos, o que incide de modo deletério no avanço das políticas no tema. $\mathrm{O}$ modo como a comunidade científica classifica e interpreta os desastres influencia as decisões de Estado em relação às interpretações do direito, às reivindicações de vítimas, à orientação de prioridades de proteção e defesa civil e outros serviços públicos (4).

Num país onde desastres proliferem, como o Brasil, seria de esperar um acalorado debate no tema, com controvérsias sobre sistemas de classificação do problema. Surpreende que aqui, contudo, esse debate não vingue. Isso se deve ao fato de que a vertente interpretativa hipervalorizada, em torno dos desastres "naturais", por estar de tal forma incrustrada no tecido institucional público, na narrativa midiática e no senso comum, pode prosseguir difundindo verdades sobre a "natureza em fúria" em total alheamento à complexidade dos aspectos sociais atinentes e ignorando qualquer contraposição interpretativa. Aproveitando a grande visibilidade atual do tema, pesquisadores que têm tradicionalmente o escopo de seus estudos em temas correlatos (drenagem urbana, tempo e clima, paisagem, ambiente, planejamento urbano) passam a se apresentar como especialistas em desastres, gerando opacidade na discriminação de expertise e exercendo pressōes indevidas na condução da política científica no tema, incluso nos processos de avaliação de projetos e na retaliação das vozes dissonantes. Seria ingênuo supor que estejam dispostos à contraposição de ideias, embora seja esse o ingrediente essencial da ciência. Ocorre que, se os ditames do conhecimento científico que inspiram e calibram a ação do Estado forem equivocados, os seus efeitos deletérios far-se-ão sentir no meio social. O corolário dessas distorções é a reiterada incompreensão pública acerca dos processos que desencadeiam catástrofes.
Uma ilustração emblemática dessas distorçóes foi a mais alta autoridade do país denominar como desastre "natural" o rompimento de barragem da empresa Samarco, ocorrido em Minas Gerais. O fezatravés do Decreto Presidencial 8.572, de 13 de novembro de 2015 (5); lê-se, em seu parágrafo único: "considera-se também como natural o desastre decorrente do rompimento de barragens que ocasione movimento de massa, com danos a unidades residenciais". A justificativa de boas intençôes palacianas no uso desse discurso - viabilizar a liberação do Fundo de Garantia por Tempo de Serviço (FGTS) para as famílias afetadas, o que já tem ocorrido em casos similares (6) - não deveria obnubilar as insuficiências do atual sistema oficial de classificação de desastres, mera reprodução acrítica do Emergency Events Database (EM-DAT) do Centro de Pesquisas em Epidemiologia de Desastres (CRED, na sigla em inglês), e a falta de providências para a atualização da legislação a fim de amparar mais apropriadamente trabalhadores formais em situaçōes adversas como essa. Tão inapropriado quanto denominar essa catástrofe de desastre "natural" foi a Presidência da República, respaldada no conhecimento técnico e científico que a assessora, mencionar no decreto presidencial datado de 12 de novembro de 2015 - que institui um Comitê de Gestão e Avaliação de Resposta - que se trata do "desastre ocorrido nas barragens de Fundão e de Santarém” [grifo nosso] entendendo como meras "repercussões" as ocorrências na bacia do rio Doce (7). Essa maneira de circunscrever o desastre em si-como se o mesmo estivesse contido nas referidas obras civis e o restante fosse apenas efeitos - evidencia despreocupação com um domínio conceitual mínimo. Isso suscita dúvidas quanto à qualidade das deliberaçôes que porventura venham a ser tomadas pelo referido comitê.

Tendo esse contexto como pano de fundo, destacamos cinco aspectos, a saber: (a) o problema da definição de desastre e qualificativos; (b) a imbricação entre desastre e crise; (c) os diversos tempos envolvidos; (d) os aspectos transescalares e, por fim; (e) a desumanização dos afetados.

\section{O PROBLEMA DA DEFINIÇÃO DE DESASTRE E DO USO DOS QUALIFI-} CATIVOS Desastre, em essência, é um problema atinente ao meio social. Uma pergunta central seria: "qual o processo social que o desencadeou?". Se acaso a pergunta central for outra, dirigida à "natureza em fúria", isso inviabiliza que os grupos afetados tenham recursos de voz. Tampouco os cientistas sociais seriam demandados a oferecer seus subsídios para o encaminhamento de providências públicas pertinentes (8). No Brasil, os pares se sentem desmotivados a se pronunciar no assunto. No entanto, se se animam a abordá-lo, convém fazê-lo numa perspectiva crítica, não se esquivando das controvérsias (9) e procurando agregar demais especialidades para tornar o panorama do problema mais rico (p. ex., 10).

Há muitas décadas, o debate sociológico considera aceitável definir um desastre como uma situação de estresse coletivo relacionada a um acontecimento físico perturbador (11). Tal relação expressaria um colapso da cultura de prevenção (12), cuja aparente subtaneidade do episódio se alimentaria de dinâmicas lentas constitutivas da normalidade da vida social. Assim, embora os desastres sejam distúrbios 
graves e multidimensionais na rotina de uma dada coletividade (13), as explicaçōes em torno dessa situação anormal não deveriam deixar de perscrutar o processo normal que a forjou. Nessa perspectiva, é difícil concordar com a racionalidade científica dominante que difunde que forças naturais "provocam" desastres, pois isso seria como que uma versão atualizada de um pensamento animista, que imputa à natureza uma intencionalidade (12). O problema-chave acaba sendo subvertido, escamoteando-se indagaçôes acerca dos modos como a sociedade produz e lida (bem ou mal) com perigos de variada natureza e/ou as razôes pelas quais adota sistemas propensos a falhar.

O uso do qualificativo "natural" a desastres catastróficos, como o relacionado ao rompimento de barragem da Samarco, se torna uma agressão simbólica àqueles severamente prejudicados nessas situaçôes, porque o fator causador não teria personalidade jurídica a responder em tribunais. É de notar que a sua eventual substituição pelo qualificativo "tecnológico" também poderia ser limitante, pois seu uso dominante não o associa às relaçôes sociais (14), limitando-se puramente a coisas - aos diques de contenção, às substâncias químicas dos rejeitos e afins - como se nelas estivesse contido o mal deflagrado e a adoção de novas tecnicalidades resolvesse o problema. Em outros casos catastróficos relacionados ao rompimento de barragens no país, constatou-se que, conforme as discussōes sobre tecnicalidades avançavam, fragmentavam-se as responsabilidades de cada sujeito (público e privado) envolvido, diluindo sua vinculação com o aspecto global da tragédia e isentando-o (15). O mesmo se poderia dizer em relação ao qualificativo "ambiental" que, em termos práticos, salienta apenas questões ecológicas passíveis de manejo técnico deixando a reboque, num jogo de esconde, os sujeitos sociais e as lógicas operativas que forjam e recrudescem tais tragédias.

Para os que vivenciam ou os que testemunham de perto, os desastres são descritos como uma conjugação insuportável de inúmeros, graves e simultâneos danos e perdas coletivas, caracterizando um imenso sofrimento social em relação ao qual é esperada, e exigida, a mobilização imediata de diversos sujeitos para prover o resgate e a reabilitação dos vitimados sobreviventes, o manejo de cadáveres e a busca por desaparecidos, seguido de medidas recuperativas correspondentes. No contexto brasileiro, a acentuada frequência dessas situações insuportáveis tem raízes na tolerância para com o espraiamento das práticas econômicas de grande escala, que atentam contra a qualidade socioambiental do meio circundante e interferem politicamente para deslegitimar o modo de vida dos lugares ameaçados. Assim, se o desastre é uma situação insuportável para a coletividade afetada, sua cronicidade pode estar atrelada ambiguamente à complacência social diante dos processos indutores de tragédias, cujas sementes se espargem pelo país na forma de megaprojetos imobiliários, agropastoris, madeireiros, esportivos, hídricos, hidrelétricos, petroquímicos, minerários e similares (16).
DESASTRES E CRISES Crises podem fabricar desastres assim como desastres podem conter inúmeras crises específicas. Ambos dizem respeito à perturbação de estruturas sociais básicas, onde as rotinas institucionais já não conseguem operar dentro do seu funcionamento normal devido à mescla de ameaças, urgências e incertezas, que passam a exigir a tomada de decisões cruciais $(17 ; 18)$.

Megaempreendimentos são sistemas gigantescos, em termos econômicos e espaciais, e cuja cultura organizacional é orientada para uma perfeita acoplagem à dinâmica do mercado ao qual estão atrelados. Quando deflagram um desastre, o meio jurídico desses sistemas age para garantir, em primeiro lugar, os interesses corporativos; tudo se passa como se um "mal maior" tivesse que ser evitado, qual seja, a eventual inviabilidade econômica da empresa para a continuidade de suas operaçōes. Nesse jogo, as medidas mitigadoras postas em curso procuram cercar-se de competências científicas e métodos que possam subestimar os danos ecológicos e sociais provocados; posterga-se o tanto quanto possível o pagamento de indenizaçōes e tornam-se lentas as medidas recuperativas. Espera-se que o "retorno à normalidade", no autoajustamento das dinâmicas ambientais e dos recursos socioecológicos sobrantes, faça desaparecer os vestígios mais comprometedores da tragédia e as alegações correspondentes dos que reivindicam compensações. Sempre que possível, as forças naturais aparecem no argumento empresarial para atenuar e mesmo contestar as suas responsabilidades no episódio e, se possível, torná-la uma das incontáveis vítimas do desastre "natural". No caso Samarco, procurou-se por sismos; depois, houve intervenção judicial para que as medidas de reabilitação fossem providenciadas pela empresa (19). Sem que houvesse a devida atenção do Ministério Público, esse modus operandi da indiferença social (20) seria ainda mais corriqueiro no Brasil.

A ideia de "retorno à normalidade" após esses desastres "naturais" costuma limitar-se a um rol de providências superficiais sobre aquilo que "deu errado", mascarando-se as raízes da crise, nas quais estão a posição do aparato estatal perante atores econômicos de peso. Esse aparato lida rotineiramente com urgências de toda a ordem, é altamente burocratizado e ineficiente, cerceando as condições de flexibilidade e agilidade que são elementos indispensáveis para a averiguação e atuação preventiva sobre potenciais ameaças (17), e sem os quais uma crise não consegue ser evitada ou debelada. Os gabinetes de crise - que visam estabelecer uma comunicação mais ágil entre os setores técnicos e operacionais estatais no afă de que adotem, o quanto antes e em comum, uma intepretação válida que justifique as providências que passam a ser tomadas - não se livram da racionalidade linear das partes constituintes, o que induz consensos interpretativos simplistas correspondentes à capacidade desse coletivo de manejar a situação (17). Isso mascara antecedentes da tragédia relacionados às ineficiências burocráticas, omissão de providências, falhas de fiscalização e desproteção social das comunidades afetadas. 
A decretação municipal de situação de emergência (SE) ou de estado de calamidade pública (ECP) indica que a crise foi oficialmente assumida e respalda que a administração pública interrompa as suas rotinas para eleger outro rol de prioridades. Esses episódios de excepcionalidade administrativa merecem ser acompanhados mais detidamente, uma vez que, no Brasil, não são tão excepcionais assim. Nos últimos cinco anos (2011-2015), a média anual de decretação de emergência no estado do Espírito Santo foi equivalente a 38,46\% dos municípios dessa unidade federativa e no estado de Minas Gerais, equivaleu a 20,58 \% dos seus municípios. Isso remete à questão: que aprendizado institucional tem havido diante de cada uma das crises com as quais se deparam?

Numa máquina administrativa com pendores mais autoritários, seguir de excepcionalidade em excepcionalidade se torna conveniente, evitando o controle social local e impondo linhas de comando que subordinam as vítimas e subtraem a sua autodeterminação (21). O que, no Brasil, imbrica desastre e crise é a persistência desse approach estatal tecnocrático, que cada vez aborda os desastres como uma operação de guerra (22).

\section{OS DIVERSOS TEMPOS E ESCALAS ENVOLTOS NUM DESASTRE Há}

duas demarcaçôes temporais de um desastre que são disseminadas pelo meio técnico de defesa civil e pelo mainstream científico: uma, associada à manifestação do evento visto como "perigo" e outra, associada aos ditames burocráticos das providências emergenciais. Tudo o mais que venha ocorrer é denominado como "pós-desastre". Esses tempos se descolam por completo do tempo do sofrimento social dos grupos afetados; para estes, as cronologias das privações antecedentes e posteriores também contam (23). E há outros tempos subjetivos e objetivos longos implicados na situação de sofrimento, vinculados à perda de objetos de memória e de identidade social.

$\mathrm{Na}$ catástrofe em tela, há variados tempos e espaços entrelaçados. Conforme a lama tóxica da barragem rompida foi descendo por afluentes e pela calha principal do rio Doce, os tempos e os conteúdos da afetação socioambiental foram se alterando, indo da devastação completa de lugares - com a morte e o desaparecimento de pessoas, de animais domésticos e de criação bem como com a destruição completa de bens móveis e imóveis - até o colapso no serviço público de abastecimento hídrico de várias cidades mineiras e capixabas à jusante (19). Isso ilustra que a restituição da "normalidade" nem sempre é viável: vidas não se restituem e histórias de vida mudam de rumo irreversivelmente após um desastre (8). Numa cronologia mais lenta vem ocorrendo o comprometimento do ecossistema aquático (24) depondo contra a integridade dos estoques pesqueiros, a segurança alimentar de comunidades ribeirinhas e a saúde humana. Esse entremear de diferentes tempos foi bem ilustrado por um jornalista, quando disse: "a memória de um bairro de 300 anos levada em pouco mais de 10 minutos, ou enterrada sob uma camada de barro, por erros de uma mineradora instalada ali perto há 39 anos" (25).

Para a defesa civil, a abrangência espacial de um desastre é representada como "cenário" para o seu "teatro de operaçôes". Mas, como processo, um desastre expande consideravelmente o espaço envolvido. Decisōes de sociedades anônimas e governos provocam a reconfiguração territorial de localidades que se supunham estáveis (26); quanto mais extensa a história local de desfiliação social, menos condições seus membros têm de reivindicar proteção; assim, quando ocorre um desastre que os envolva, menor proficiência estes têm para lidar com a burocracia gerencial da crise (4). Como, numa entrevista a um jornal, salientou uma das moradoras afetadas do povoado de Bento Rodrigues, já violentada moralmente por constatar a disseminação dos rumores de que as vítimas seriam oportunistas: "Não fomos nós que construímos nossas casas embaixo da barragem, mas a barragem que foi construída em cima delas" (25).

O ajustamento hierárquico dos territórios aos ditames do mercado globalizado é um dos aspectos da articulação entre a ação econômica e política que, nos desastres, define limites mais restritos à vida biológica ao derredor, uma biopolítica (27). Isso é legitimado pela disposição sociocultural a aceitar objetos técnicos colossais resultantes de um elevado nível de articulação tecnopolítica de seus empreendedores (28), o que sufoca eventuais contestaçōes encaminhadas para instâncias decisórias (29). Essa arquitetura de poder produz margens sociais onde a ideia de segurança é tênue; lá, o meio técnico se faz presente para denunciar suscetibilidades geológicas, hidrológicas, infraestruturais, anunciá-las como "áreas de risco" e promover uma dissolução final do lugar, tratando a comunidadelocal como um refugo humano (30). O reforçoà estigmatização social dos residentes nessas bordas do mundo se dá através das paredes de suas casas, pintadas com códigos de defesa civil, respaldando o ato violento de "remoção" dos moradores para um não-lugar, como se fossem objetos. Essas tecnicalidades desumanizadoras insistem em perder de vista a compreensão do risco como processo relacional político e econômico entre diferentes espaços. No caso em tela, desde a comunidade de Bento Rodrigues, no município de Mariana, até centenas de quilômetros da foz do rio Doce viraram uma mesma "área de risco".

OUTRAS FACETAS DA DESUMANIZAÇÃO Embora a literatura assinale que o altruísmo seja o comportamento social preponderante em contexto de desastre (31), outros casos de catástrofes no Brasil demonstraram que, passado um breve período de uma reabilitação emergencial, as medidas recuperativas foram limitadas e o abandono das vítimas foi a regra (32), pois a marginalização histórica dos afetados autorizava a prática de slow violence (33) contra os mesmos. Denominar as medidas usuais de reabilitação como "assistência humanitária" deixa escapar a dimensão da cidadania e o fato de que os programas humanitários pouco lutam pelo justo ressarcimento àqueles que tudo perdem numa tragédia (34).

No contexto mineiro, cientistas sociais apontaram que a comunidade de Bento Rodrigues tinha receio de rompimento de barragem há anos e, após a concretização do desastre, o assédio da empresa teria se tornado constante, constrangendo as condiçôes reivindicativas comunitárias (35). Já no contexto capixaba, um estudo similar apontou a junção de aspectos concretos e simbólicos; graves 
problemas no abastecimento hídrico, na irrigação de lavouras, na pesca e no turismo e lazer, além dos danos ecológicos, associaram-se à violência policial contra manifestantes e à dor comunitária de presenciar o rio Doce em agonia, contrapondo-se a sua memória afetiva do lugar (36). Tais esgarçamentos e descontinuidades na vida social não ocorreram somente nesse desastre, mas em inumeráveis outros, nos quais cientistas sociais precisariam ser apoiados para se debruçar com densidade de análise.

Enfim, seria apreciável uma ciência robusta sobre tais processos, ainda mais, cientistas sociais com criticidade. Nos primeiros dias em que corpos ainda estavam sendo resgatados da lama tóxica e outros continuavam desaparecidos, houve cientista social difundindo o chavão de que "crise é oportunidade", que a literatura já advertia ser deplorável (37), e concebesse como proativo um discurso de exaltação a negócios "sustentáveis" em torno da lama tóxica (p. ex., 38). Nem mesmo os dirigentes da empresa responsável pela catástrofe tinham ido tão longe.

À GUISA DE CONCLUSÃO Os estudos sobre desastres não deveriam prescindir ou marginalizar as ciências sociais, cujas competências no assunto, quando assentadas numa base crítica, trazem à baila aspectos cruciais do problema, ora subestimados. Uma zona de conforto interpretativa das vozes dominantes vai corroendo os princípios da ciência; simplificando a concepção de vida social. Isso obstrui uma melhor compreensão dos danos e do tratamento social dispensado às vítimas; da qualidade das operações de emergência e das condições de trabalho do meio operacional; dos critérios utilizados na imputação de responsabilidades e cobrança de providências; entre outros. Se a ciência se abstiver de adotar uma visão mais ampla do problema, talvez veículos de imprensa e mídias sociais passem a contestar as verdades emanadas nos laboratórios e replicadas nos gabinetes políticos e na gestão técnica das emergências (4; 39); quem sabe estes consigam descobrir que há aparatos que colhem compensaçóes na letargia do aprendizado social com as crises (37).

A proliferação e a recorrência de decretação e reconhecimento de estados de exceção (SE e ECP) por todo o país assinala a ineficiência e mesmo a falência de certos aspectos rotineiros da gestão pública, um desastre institucional englobante dos desastres "naturais". O caso relacionado ao rompimento da barragem de Fundão, da empresa Samarco, é o episódio mais emblemático em vista de seu multifacetado, extenso e duradouro caráter destrutivo e reforça a progressiva desconfiança da sociedade na capacidade de ação preventiva das instituições públicas. As estratégias exitosas de acumulação da indústria extrativista estão hoje embebidas em muita ciência e técnica; mas essas parecem ineficientes na contenção dos graves malefícios socioambientais gerados. Por seu turno, as forças políticas dominantes se encontram demasiado obstinadas na concretização de sua questionável visão de progresso que as liga a tais investimentos, pois isso amplia o seu capital social e garante a continuidade de seu controle sobre o aparato estatal. Nisso, atuam abertamente na supressão de medidas socioambientais precaucionárias o que, de um lado, torna a governança de riscos uma mera ideologia e, de outro, faz despontar uma sequência de desastres catastróficos num futuro próximo. As catástrofes que abundam são um reservatório de lições preciosas sobre planos de contingência falhos (18), culturas institucionais alienadas e escolhas sociais equivocadas.

Dito isso, duas direções opostas parecem despontar com alguma nitidez num horizonte de incertezas. A primeira indica que, quanto mais recorrentes e espraiados forem os desastres no contexto nacional, maior a possibilidade dos mesmos se tornarem situações socialmente toleráveis aos que as testemunham, integradas na rotina do desenvolvimento desigual. A segunda direção aponta para um esgotamento da tolerância social diante da repetição de tais episódios, ponto no qual poderá crescer a pressão sobre o aparato estatal para exigir o aprendizado, sempre protelado, sobre as razões profundas dessas crises evitáveis. O tempo dirá se essas ou outras direções alternativas se abrirão à nossa frente.

Norma Valencio é economista, mestre em educação e doutora em ciências humanas. Professora aposentada do Departamento de Sociologia da Universidade Federal de São Carlos (UFSCar), onde coordenou (2005-2015) o Núcleo de Estudos e Pesquisas Sociais em Desastres (Neped). É professora colaboradora do Programa de Pós-Graduação em Ciências da Engenharia Ambiental da EESC/USP-São Carlos e consultora independente em sociologia dos desastres.

\section{REFERÊNCIAS}

1. Quarantelli, E.L.. "Introduction: the basic question, its importance, and how it is addressed in this volume". In: What is a disaster? Perspectives on the question. Routledge, New York, pp 1-7. 1998.

2. Lavell, A.. "Ciencias sociales y desastres naturales en América Latina: un encuentro inconcluso". In: Los desastres no son naturales. A. Maskrey (Ed.). Red de Estudios Sociales en Prevención de Desastres en América Latina, Ciudad de Panamá, pp. 111-125. 1993.

3. Jones, S.. "World heading for catastrophe over natural disasters, risk expert warns". The Guardian, 24/04/2016. Disponível online.

4. Drake, P.. "Multiple visions of Indonesia's mud volcano: understanding representations of disaster across discursive settings". Disasters, vol.40 (2), 346\$364, 2016.

5. Rousseff, D.; Rosseto, M.; Occhi, G.M.. Atos do Poder Executivo: Decreto $n^{\circ} .8572$, de 13 de novembro de 2015 (Altera o Decreto $n^{\circ} 5.113$, de 22 de junho de 2004). Diário Oficial da União, seção 1, edição extra, 13/11/2015. http://pesquisa.in.gov.br/imprensa/jsp/visualiza/index. jsp?jornal=1000\&pagina $=1 \&$ data $=13 / 11 / 2015$

6. Valencio, N.. Para além do 'dia do desastre': o caso brasileiro. Appris, Curitiba, 2012.

7. Rousseff, D.; Occhi, G.M.; Atos do Poder Executivo: Decreto de 12 de novembro de 2015 (Institui o Comitê de Gestão e Avaliação de Respostas ao desastre...). Diário Oficial da União, seção 1, 13/11/2015. http://pesquisa.in.gov.br/imprensa/jsp/visualiza/index.jsp?data=13/11/2015\&jornal=1\&pagina $=6 \&$ total Arquivos $=336$ 
8. Perry, R.. "What is a disaster?" In: Handbook of disaster research, Rodriguez, H.; Quarantelli, E.; Dynes, E. (eds). Springer, New York, 2007, pp. 1-16.

9. Quarantelli, E.L.. "The social science study of disasters and mass communication". In: Bad tidings: communication and catastrophe, Walters, L.M.; Wilkins, L.; Waltems, T. (eds). Lawrence Erlbaum Assoc., Hillsdale, NJ, 1989, pp. 1-19.

10. Siqueira, A.; Valencio, N.; Siena, M.; Malagoli, M.A.. (eds.). Riscos de desastres relacionados à água: aplicabilidade de bases conceituais das ciências humanas e sociais para a análise de casos concretos. RiMa, São Carlos, 2015.

11. Fritz, C.E.. "Disaster". In: Contemporary social problems, Merton, R. K.; Nisbet, R. A. (eds.). Harcourt, New York, pp. 651-694. 1961.

12. Dombrowsky, W.R.. "Again and again: is a disaster what we call a "disaster". In: What is a disaster? Perspectives on the question. Quarantelli, E.L. (ed.) Routledge, New York, pp. 19- 30.1998.

13. Quarantelli, E.L.. "A social science research agenda for disasters of the 21st Century: theoretical, methodological and empirical issues and their professional implementations". In: What is a disaster? New answers to old questions, Perry, R.W.; Quarantelli, E.L. (eds). (International Research Committee on Disasters and Xlibris, Bloomington, IN, 2005), pp. 325-396.

14. Benakouche, R.. "Que tecnologia para qual sociedade?" Revista da Fundação de Economia e Estatística, vol.9 (88), pp.3-63.1984.

15. Valencio, N.. "Vivência de um desastre: uma análise sociológica das dimensões políticas e psicossociais envolvidas no colapso de barragens". In: Sociologia dos desastres: construção, interfaces e perspectivas no Brasil. Valencio, N.; Siena, M.; Marchezini, V.; Gonçalves, J.C. (eds.). RiMa, São Carlos, vol.1, pp. 176-196. 2009.

16. Oliver-Smith, A. "Theorizing disasters: nature, power, and culture". In: Catastrophe and culture: the anthropology of disasters. Hoffmann, S.M.; Oliver-Smith, A. (eds.) School of American Research Press, Santa Fé, chap. 2. 2002.

17. Boin, A.; Ekengren, M.; Rhinard, M.. "The study of crisis management". In: The routledge handbook of security studies, Mauer, V.; Cavelty, M.D. (eds). Routledge, London, 2012, pp. 452-462.

18. Boin, A.; t'Hart, P.. "The crisis approach". In: Handbook of disaster research, Rodríguez, H.; Quarantelli, E.L.; Dynes, R.R. (eds). Springer, New York, 2007, pp. 42-54.

19. Milanez B. et al., "Antes fosse mais leve a carga: avaliação dos aspectos econômicos, políticos e sociais do desastre da Samarco/Vale/BHP em Mariana (MG)". Relatório Final, Mimeo e UFJF, Juiz de Fora, 2015.

20. Cohn, G.. "Indiferença, nova forma de barbárie" In: Civilização e barbárie, Novaes, A. (ed). Companhia das Letras, São Paulo, 2004, pp. 81-90.

21. Das, V.. Critical events: an anthropological perspective on contemporary India. Oxford Univ. Press, New Delhi, 1995.

22. Valencio, N.. "Dos desastres recorrentes aos desastres à espreita". In: Formas de matar, de morrer e de resistir: limites da resolução negociada de conflitos ambientais, Zhouri, A.; Valencio, N. (eds). Ed.UFMG, Belo Horizonte, 2014, p. 277-316.
23. Sorokin, P.. Man and society in calamity: the effects of war, revolution, famine, pestilence upon human mind, behavior, social organization and cultural life. Dutton, E.P. and Co. Inc., New York, 1942.

24. Fioravanti, C. "Impactos visíveis no mar". Pesquisa Fapesp, 242, 42-47 (2016).

25. Mendes, G. "Identidades rompidas". O Estado de S. Paulo, Aliás, 30/4/2016. Disponível online.

26. Santos, M.. "As cidadanias mutiladas". In: O preconceito, Lerner, J. (ed). Imprensa Oficial do Estado, São Paulo, 1996, pp. 133-144.

27. Agambem, G. Homo sacer: o poder soberano e a vida nua. Ed.UFMG, Belo Horizonte, 2004.

28. Ribeiro, G.L. "Poder, redes e ideologia no campo do desenvolvimento". Novos Estudos Cebrap, 80, 109-125. 2008.

29. Bermann, C.. "A desconstrução do licenciamento ambiental e a invisibilização do social nos projetos de usinas hidrelétricas". In: Formas de matar, de morrer e de resistir: limites da resolução negociada de conflitos ambientais, Zhouri, A.; Valencio, N. (eds). Ed.UFMG, Belo Horizonte, 2014, pp. 95-109.

30. Bauman, Z. Vida em fragmentos: sobre a ética pós-moderna. Zahar, Rio de Janeiro, 2011.

31. Quarantelli, E.; Lagadec, P.; Boin, A.. "A heuristic approach to future disasters and crises: new, old, and in-between types". In: Handbook of disaster research, Rodríguez, H.; Quarantelli, E.L.; Dynes, R.R. (eds). Springer, New York, 2007, pp. 16-41.

32. Valencio, N.; Siena, M.; Marchezini, V.. Abandonados nos desastres: uma análise sociológica de dimensões objetivas e simbólicas de afetação de grupos sociais desabrigados e desalojados. Conselho Federal de Psicologia, Brasília, 2011.

33. Nixon, R. Slow violence and the environmentalism of the poor. Harvard Univ. Press., Cambridge, MA, 2011.

34. Mallett, R.; Slater, R. "Livelihoods, conflict and aid programming: is the evidence base good enough?". Disasters, 40 (2):226-245. 2016.

35. Zhouri, A. Representação ao Ministério Público do Estado de Minas Gerais (MPE) e à Procuradoria da República em Minas Gerais (MPF-MG) Relatório Técnico, MPE-MG, MPF-MG e UFMG, Belo Horizonte, 2016.

36. C. Losekann C. et al., "Sem-terra, sem-água e sem-peixe - impactos socioambientais da ruptura da barragem de rejeitos da Samarco no Espírito Santo". Cadernos de Trabalho da Rede Waterlat-Gobacit, 2 (17), 8-35. 2015.

37. Boin, A.; t'Hart, P.. "Learning to learn from crisis: the hardest challenge". In: Organizing after crisis: the challenge of learning, Schiffino, N.; Taskin, L.; Donis, C.; Raone, J. (eds). Peter Lang Verlag., Brussels, 2015, Public Action Series vol. 13, pp.13-15.

38. Jacobi, P. "Lama da Samarco: desastre ou oportunidade econômica?". Geofísica Brasil, 13/11/2015. http://www.geofisicabrasil.com/notícias/204-clipping/7655-lama-da-samarco-desastre-ou-oportunidade-economica.html

39. Alexander, D. "Social media in disaster risk reduction and crisis management". Sci. Eng. Ethics., 20 (3), 717-33. 2014. 